Short Note

\title{
N"-[(3Z)-1-Acetyl-5-chloro-2-oxo-1,2-dihydro-3H-indol-3- ylidene]thiocarbonohydrazide
}

\author{
Nataša Ristovska *, Frosa Anastasova and Marina Stefova \\ Institute of Chemistry, Faculty of Natural Sciences and Mathematics, Ss. Cyril and Methodius University, \\ Gazi baba bb, 1000 Skopje, Macedonia
}

* Author to whom correspondence should be addressed; E-Mail: ristovska.natasha@on.net.mk; Tel. +38-923-249-914; Fax +38-923-228-141.

Received: 8 February 2013 / Accepted: 9 April 2013 / Published: 16 April 2013

\begin{abstract}
A novel synthetic methodology for preparation of thiocarbohydrazone by reacting thiocarbohydrazide with 1-acetyl-5-chloroisatin is described. The title compound was prepared by condensation of thiocarbohydrazide and substituted isatin in aqueous ethanol. The newly synthesized compound was characterized using ${ }^{1} \mathrm{H}-\mathrm{NMR},{ }^{13} \mathrm{C}-\mathrm{NMR}$, FT-IR and mass spectrometry.
\end{abstract}

Keywords: chloroisatin; thiocarbohydrazide; carbonyl-amine condensation

\section{Introduction}

Isatin (indoline-2,3-dione), possessing an indole nucleus with two chemically distinct cyclic carbonyl groups, keto and lactam, has provoked tremendous interest due to its numerous biological and pharmacological activities. The growing importance of substituted isatins in the field of medicinal chemistry as potential chemotherapeutic agents and their implication for pro-drug design have been previously reported [1-9].

Particular attention has been paid to the structural perturbations caused by 5-substitution. Antimicrobial activity studies revealed that substitution in the 5th position of isatin with strong electron-donating atoms/groups, such as chlorine, bromine or fluorine, produced more active compounds in a series compared to the parent molecule [10-12]. This observation encouraged us to further study the reactions of 5-halo substituted isatin heterocycles with carbohydrazide and thiocarbohydrazide in order to obtain new derivatives [13]. 
In the last decades several isatin heterocycles with hydrazine moiety have been prepared that exhibited remarkable biological activity including antimicrobial, antitubercular, antiviral, antiinflammatory, anticonvulsant, antihypertensive, hypoglycemic, cytotoxic, anticancer activity and enzymatic inhibition [14]. The Schiff-bases of the isatin analogs also showed inhibitory activity against eLF2 kinase activator [15], TNF- $\alpha$, CDK2 [16] and SARS protease [17]. In addition, isatin- $\beta$ thiosemicarbazone derivatives possess a range of chemotherapeutical activities $[18,19]$.

Considering the fact that the thiocarbohydrazone group is necessary for antimicrobial activity [20], we have investigated the carbonyl-amine reactions of some isatin derivatives and we have observed that $N$-ethylisatin- $\beta$-thiocarbohydrazone has cytostatic activity towards malignant melanoma cells [9]. Herein we report the synthesis and spectral characterization of the novel derivative $N^{\prime \prime}-[(3 Z)$-1-acetyl5-chloro-2-oxo-1,2-dihydro-3H-indol-3-ylidene]thiocarbonohydrazide (4).

\section{Results and Discussion}

The title compound 4 was obtained via three steps as described in Scheme 1. The first step involved synthesis of isatin derivative 5-chloroindoline-2,3-dione (2) using a modified Sandmeyer methodology [21]. It was prepared with dehydrative cyclization of the precursor 4-chloroisonitrosoacetanilide (1) with concentrated $\mathrm{H}_{2} \mathrm{SO}_{4}$ at controlled temperature. Compound $\mathbf{1}$ was synthesized in very good yield by reaction of the respective aromatic amine 4-chloroaniline (a) with chloral hydrate and hydroxylamine hydrochloride.

Scheme 1. Synthesis of $N^{\prime \prime}$-[(3Z)-1-acetyl-5-chloro-2-oxo-1,2-dihydro-3H-indol-3ylidene]thiocarbonohydrazide (4).

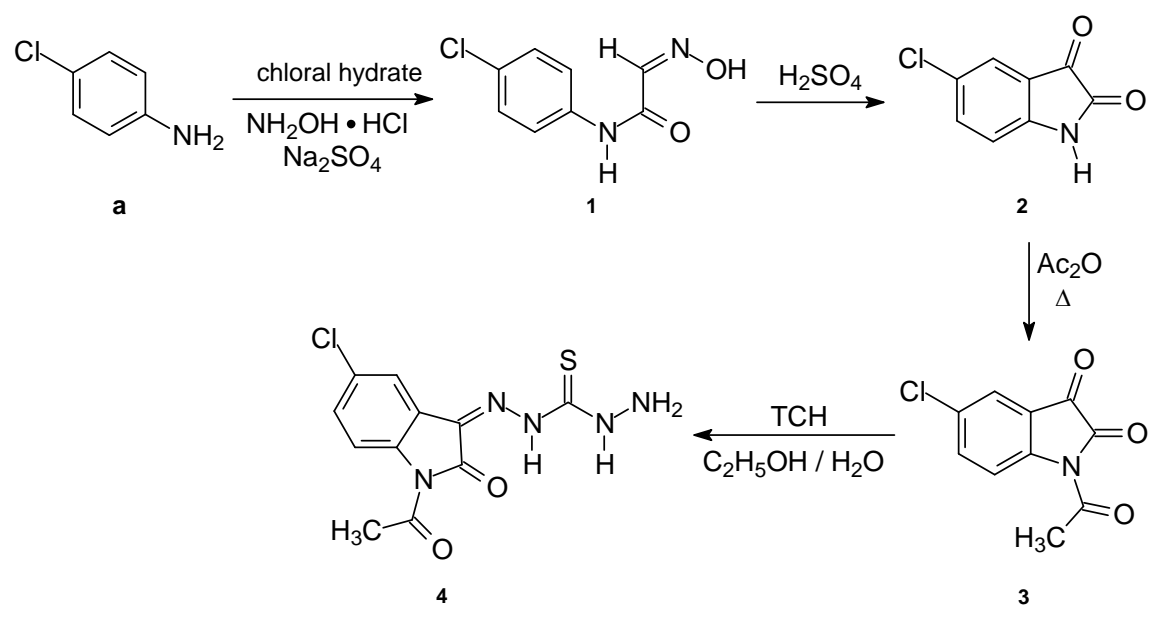

In order to hinder the formation of isatin-like centrosymmetric dimers in the carbonyl-amine reaction of 2 with thiocarbohydrazide, the second step was $N$-substitution of 5-chloroindoline-2,3dione (2) to obtain the corresponding 1-acetyl derivative (3). 1-Acetyl-5-chloroindoline-2,3-dione (3) was prepared by adapting a literature method [22].

Finally, in the carbonyl-amine condensation of the disubstituted isatin (3) with thiocarbohydrazide $(\mathrm{TCH})$, synthesized according to the Taguchi method [23], 4 was obtained. In order to improve the yield of 4 , the effect of the mole ratio of reactants and the amount of solvents was investigated. It was 
found that the corresponding isatin product was predominantly obtained by using equimolar amounts of 3 and $\mathrm{TCH}$, in ethanol/water $(3: 1, v / v)$ as a solvent system.

The structure of the title compound (4) was confirmed using FT-IR, ${ }^{1} \mathrm{H}-\mathrm{NMR},{ }^{13} \mathrm{C}-\mathrm{NMR}$ and $\mathrm{MS}^{n}$.

Complex bands dominate in the 3,500-2,800 $\mathrm{cm}^{-1}$ spectral region of $N^{\prime \prime}$-[(3Z)-1-acetyl-5-chloro-2oxo-1,2-dihydro-3H-indol-3-ylidene]thiocarbonohydrazide. The band at around $3,315 \mathrm{~cm}^{-1}$ can be attributed with great certainty to $v(\mathrm{NH})$. The most prominent bands in the spectrum of the synthesized compound (4) are the ones due to the carbonyl stretchings $v(\mathrm{C}=\mathrm{O})$ of the keto and lactam group in the region around $1,700 \mathrm{~cm}^{-1}$. The absence of carbonyl $(\mathrm{C}=\mathrm{O})$ peak at around $1,750 \mathrm{~cm}^{-1}$ characteristic for the keto group in (3) could explain the formation of a thiocarbohydrazone.

The ${ }^{1} \mathrm{H}-\mathrm{NMR}$ spectra of (4) displayed three separate singlets at 14.15, 9.54 and $6.62 \mathrm{ppm}$ which can be attributed to $\mathrm{C}=\mathrm{NN}-\mathrm{H}, \mathrm{C}=\mathrm{NNH}(\mathrm{CS}) \mathrm{N}-\mathrm{H}$ and $\mathrm{C}=\mathrm{NNH}(\mathrm{CS}) \mathrm{NH}-\mathrm{NH}_{2}$ from the thiocarbohydrazide moiety, respectively. The assigment of the peak at $\delta 14.15$ as $\mathrm{C}=\mathrm{NN}-\mathrm{H}$ is supported by its location at a lower field (indicative of an intramolecularly hydrogen-bonded proton) [24]. According to the spectral data analysis, the synthesized monothiocarbohydrazone is a Z-geometrical isomer.

The mass spectrum (MS) of (4) was obtained by electrospray ionization in the negative mode and it demonstrated a molecular ion $[\mathrm{M}-\mathrm{H}]^{-}$at $\mathrm{m} / z 310$ as a base peak in $\mathrm{MS}^{1}$ with the corresponding $\mathrm{M}+2$ peak at $m / z 312$ due to the ${ }^{37} \mathrm{Cl}$ (Figure 1). The base peak in $\mathrm{MS}^{2}$ was observed at $\mathrm{m} / \mathrm{z} 236$ with isotopic peaks at 237 and 238, which results from cleavage of the $-\mathrm{CSNHNH}_{2}$ part of the molecule. Fragments at $\mathrm{m} / \mathrm{z}$ 208, 194 and 166 with low intensity (1\%-2\%) were also observed in $\mathrm{MS}^{2}$. Further fragmentation of the ion at $\mathrm{m} / z 236$ in $\mathrm{MS}^{3}$ led to two main fragments at $\mathrm{m} / z 194$ and 166 followed by their corresponding isotopic peaks. The peak at $\mathrm{m} / \mathrm{z} 194$ is due to a loss of an acetyl group, and the peak at 166 to a further loss of $\mathrm{CO}$, which occurs in amides as Claisen rearrangement [25].

Figure 1. ESI MS spectra of $N^{\prime \prime}$-[(3Z)-1-acetyl-5-chloro-2-oxo-1,2-dihydro-3H-indol-3ylidene]thiocarbonohydrazide (4).

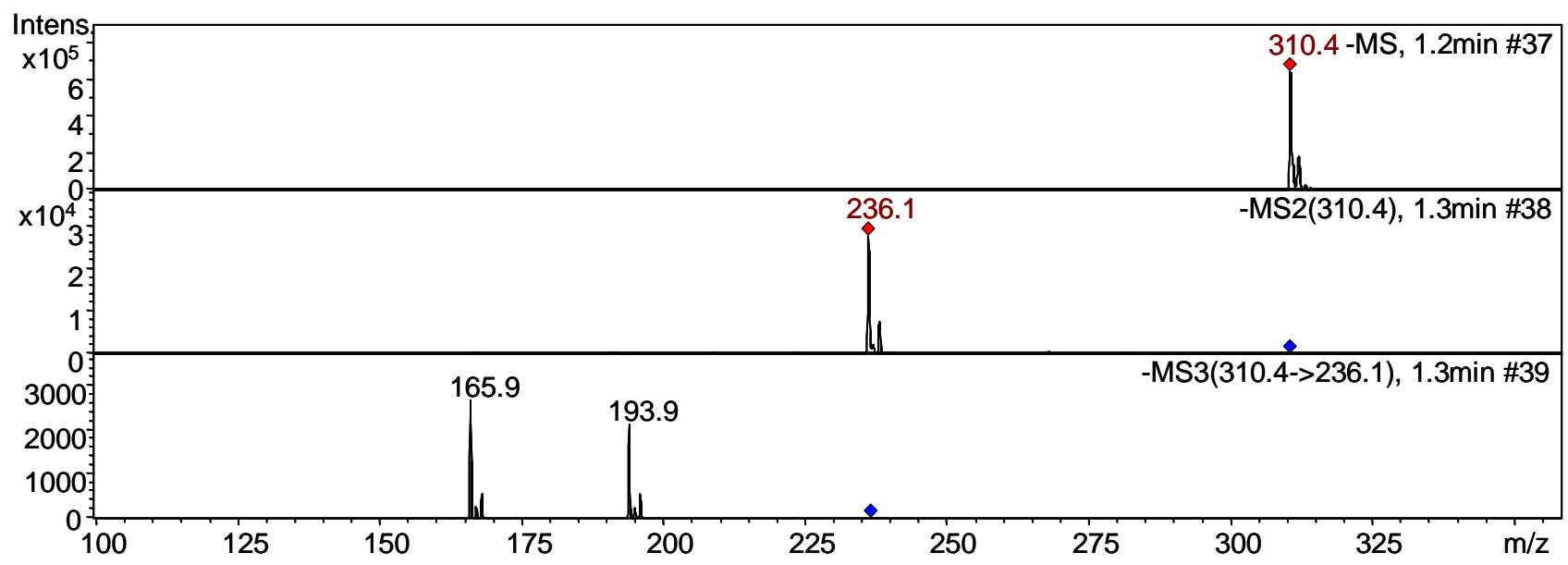

\section{Experimental}

\subsection{General}

Melting points were determined using Koffler apparatus and were uncorrected. C, H elemental analysis was carried out with Coleman Model 33. N elemental analysis was carried out by the Dümas 
method. Infrared spectra (KBr pellets) were measured on a Perkin-Elmer System 2000 FT-IR. NMR spectra were recorded on Gemini NMR Spectrometer $(200 \mathrm{MHz})$ determined in either DMSO- $d_{6}$ or $\mathrm{CDCl}_{3}$ as solvent and using tetramethylsilane as internal standard. The mass spectrometer was a G2449A Ion-Trap Mass Spectrometer (Agilent Technologies Inc., Santa Clara, CA, USA) equipped with an electrospray ionisation (ESI) system and controlled by LCMSD software v.6.1. A syringe pump (kdScientific) was used for introducing the sample in the MS with a flow rate of $1.5 \mathrm{~mL} / \mathrm{h}$. Nitrogen was used as a nebulizing gas at pressure of $12 \mathrm{psi}$ and the flow was adjusted to $5 \mathrm{~L} \cdot \mathrm{min}^{-1}$. The heated capillary and the voltage were maintained at $350{ }^{\circ} \mathrm{C}$ and $3.5 \mathrm{kV}$, respectively. MS data were acquired in the negative ionization mode. The full scan covered the mass range $m / z \quad 100-1,000$. Collisioninduced fragmentation experiments were performed in the ion trap using helium as collision gas, with voltage ramping cycle from 0.3 up to $2 \mathrm{~V}$. Maximum accumulation time of the ion trap and the number of MS repetitions to obtain the MS average spectra were set at $300 \mathrm{~ms}$ and 5, respectively.

Preparative flash chromatography was performed using Merck silica gel 60 (230-400 mesh) and thin layer chromatography (TLC) was carried out on aluminum sheets with silica gel with fluorescent indicator $(254 \mathrm{~nm})$, obtained from Sigma-Aldrich. Spots were visualized using either UV-lamp at $254 \mathrm{~nm}$ or iodine.

\subsection{Preparation Procedures}

All chemicals used for synthesis and purification were of p.a. grade (Merck). Commercial isatin was recrystallized twice from ethanol. Compounds 1, 2 and $\mathbf{3}$ are not commercially available and they were prepared by adapting reported methods $[2,21,22]$. The Sandmeyer methodology was modified as described below. 4-chloroisonitrosoacetanilide (1). The reaction mixture was refluxed for $30 \mathrm{~min}$ and the desired product was obtained by recrystallization from ethanol $(86 \%)$ m.p. $160{ }^{\circ} \mathrm{C}$ (lit. [2] rec. EtOAc, $170-172{ }^{\circ} \mathrm{C}$ ). 5-chloroindoline-2,3-dione (2). 4-Chloroisonitrosoacetanilide (1) was added to a pre-warmed concentrated sulfuric acid $\left(70-75{ }^{\circ} \mathrm{C}\right)$, at such a rate as to maintain the reaction temperature between 85 and $90{ }^{\circ} \mathrm{C}$. After the addition, the reaction mixture was heated at $95-100{ }^{\circ} \mathrm{C}$ for $15 \mathrm{~min}$. The red product 2 was obtained via recrystallization from 50\% aqueous acetic acid (92\%). M.p. $250{ }^{\circ} \mathrm{C}$ (lit. [2] rec. EtOAc, $230-232{ }^{\circ} \mathrm{C}$ ). The spectroscopic data matched those reported in the literature [2].

$N^{\prime \prime}$-[(3Z)-1-Acetyl-5-chloro-2-oxo-1,2-dihydro-3H-indol-3-ylidene]thiocarbonohydrazide. A solution of thiocarbohydrazide $(0.53 \mathrm{~g}, 5 \mathrm{mmol})$ in $10 \mathrm{~mL}$ hot water was added in small aliquots to 1-acetyl-5chloroindoline-2,3-dione $(1.12 \mathrm{~g}, 5 \mathrm{mmol})$ in $30 \mathrm{~mL}$ of ethanol. The mixture was refluxed for five minutes and then was stirred overnight at room temperature. The resulting yellow precipitate was collected by vacuum filtration, washed with ethanol/water solution $(3: 1, v / v)$ and air dried. Bright yellow solid was obtained after recrystallization from ethanol in typical yield of $70 \%$.

M.p.: $252-253{ }^{\circ} \mathrm{C}$

FTIR (KBr, $\left.\mathrm{cm}^{-1}\right): v(\mathrm{NH}) 3319,3192,3174,3140, v(\mathrm{CO})$ 1672, v(CO) lactam 1605. 
${ }^{1} \mathrm{H}-\mathrm{NMR}\left(200 \mathrm{MHz}, \mathrm{DMSO}-d_{6}\right): \delta / \mathrm{ppm} 14.15$ (s, 1H, NH, C=N-NH-CS), 9.54 (s, 1H, NH CSNHNH ${ }_{2}$ ), 6.62 (s, 2H, CSNHNH 2 ), 7.9-7.47 (m, 3H, Ar-H), 2.01 (s, 3H, $\mathrm{CH}_{3} \mathrm{CO}$ ).

${ }^{13} \mathrm{C}-\mathrm{NMR}\left(200 \mathrm{MHz}, \mathrm{DMSO}-d_{6}\right)$ : $\delta / \mathrm{ppm} 182.87(\mathrm{C}=\mathrm{S}), 168.68\left(\mathrm{C}=\mathrm{O}, \mathrm{NCOCH}_{3}\right), 148.64(\mathrm{C}=\mathrm{O}$, lactam $), 143.34(\mathrm{C}=\mathrm{N}), 136.38\left(\mathrm{C}_{\mathrm{Ar}}\right), 130.71\left(\mathrm{C}_{\mathrm{Ar}}\right), 130.18\left(\mathrm{C}_{\mathrm{Ar}}\right), 127.59\left(\mathrm{C}_{\mathrm{Ar}}\right), 125.63\left(\mathrm{C}_{\mathrm{Ar}}\right), 125.00$ $\left(\mathrm{C}_{\mathrm{Ar}}\right), 24.15\left(\mathrm{NCOCH}_{3}\right)$.

MS $m / z:[\mathrm{M}-\mathrm{H}]^{-}$at $310(100 \%)$ represents the molecular ion with formula $\mathrm{C}_{11} \mathrm{H}_{10}{ }^{35} \mathrm{ClN}_{5} \mathrm{O}_{2} \mathrm{~S}$ (minus one $\mathrm{H}$ due to the negative ionization mode). The corresponding isotopic peak (for ${ }^{37} \mathrm{Cl}$ ) was observed at $m / z 312(26.1 \%)$.

$\mathrm{MS}^{2} \mathrm{~m} / z: 236(100 \%), 237$ (7.5\%), 238 (28.0\%), 208 (1.5\%), 194 (1\%), $166(1.5 \%)$.

$\mathrm{MS}^{3} \mathrm{~m} / \mathrm{z}: 194$ (91.1\%), 195 (10.2\%), 196 (20.5\%), 166 (100\%), 167 (11.7\%), 168 (22.6\%).

Anal. Calcd. for $\mathrm{C}_{11} \mathrm{H}_{10} \mathrm{ClN}_{5} \mathrm{O}_{2} \mathrm{~S}$ (311.75): C, 42.38; H, 3.23; N, 22.46. Found: C, 42.22; H, 3.16; N, 22.25.

\section{Conclusions}

The isatin derivatives are very useful synthetic intermediates and can function as suitable building blocks for preparation of other biologically active compounds. The $N^{\prime \prime}$-[(3Z)-1-acetyl-5-chloro-2-oxo1,2-dihydro-3H-indol-3-ylidene]thiocarbonohydrazide was synthesized in good yield and its identity was confirmed using FT-IR, ${ }^{1} \mathrm{H}-\mathrm{NMR},{ }^{13} \mathrm{C}-\mathrm{NMR}$ and $\mathrm{MS}^{n}$. The biological properties and the crystal structure of the newly synthesized 4 will be thoroughly investigated.

\section{References}

1. Mariappan, P.; Srinivasan, R.; Kumarasamy, K.; Ganesan, S.; Velayutham, T.; Thangavel, S.; Kandasamy, K. Antioxidant and anticancer activities of isatin (1H-indole-2,3-dione), isolated from the flowers of Couroupita guianensis Aubl. Indian J. Med. Res. 2012, 136, 822-826.

2. Islam, M.R.; Mohsin, M. Synthesis of isatin, 5-chloroisatin and their $\Delta^{2-1}, 3,4$ oxadiazoline derivatives for comparative cytotoxicity study on brine shrimp. Bangladesh J. Pharmacol. 2007, 2, 7-12.

3. Matesic, L.; Locke, J.M.; Bremner, J.B.; Pyne, S.G.; Skropeta, D.; Ranson, M.; Vine, K.L. $N$-phenethyl and $N$-naphthylmethyl isatins and analogues as in vitro cytotoxic agents. Bioorg. Med. Chem. 2008, 16, 3118-3124.

4. Gao, N.; Kramer, L.; Rahmani, M.; Dent, P.; Grant, S. The three-substituted indolinone cyclindependent kinase 2 inhibitor 3-[1-(3H-imidazol-4-yl)-meth-(Z)-ylidene]-5-methoxy-1,3-dihydroindol-2-one (SU9516) kills human leukemia cells via down-regulation of Mcl-1 through a transcriptional mechanism. Mol. Pharmacol. 2006, 70, 645-655.

5. Wang, F.; Fang, Y.; Zhu, T.; Zhang, M.; Lin, A.; Gu, Q.; Zhu, W. Seven new prenylated indole diketopiperazine alkaloids from holothurianderived fungus Aspergillus fumigatus. Tetrahedron 2008, 64, 7986-7991. 
6. $\quad$ Lane, M.E.; Yu, B.; Rice, A.; Lipson, K.E.; Liang, C.; Sun, L.; Tang, C.; McMahon, G.; Pestell, R.G.; Wadler, S. A novel cdk2-selective inhibitor, SU9516, induces apoptosis in colon carcinoma cells. Cancer Res. 2001, 61, 6170-6177.

7. Patyna, S.; Laird, A.D.; Mendel, D.B.; O’Farrell, A.M.; Liang, C.; Guan, H.; Vojkovsky, T.; Vasile, S.; Wang, X.; Chen, J.; et al. SU14813: A novel multiple receptor tyrosine kinase inhibitor with potent antiangiogenic and antitumor activity. Mol. Cancer Ther. 2006, 5, 1774-1782.

8. Li, H.H.; Zheng, X.H.; Tan, J.Z.; Chen, L.L.; Liu, H.; Luo, X.M.; Shen, X.; Lin, L.P.; Chen, K.X.; Ding, J.; et al. Design, synthesis, antitumor evaluations and molecular modeling studies of novel 3,5-substituted indolin-2-one derivatives. Acta Pharmacol. Sin. 2007, 28, 140-152.

9. Juranić, Z.; Anastasova, F.; Juranić, I.; Stanojković, T.; Radulović, S.; Vuletić, N. Antiproliferative action of isatine- $\beta$-thiocarbohydrazone and $N$-ethylisatine- $\beta$-thiocarbohydrazone on human PBMC and on two neoplastic cell lines. J. Exp. Clin. Cancer Res. 1999, 18, 317-324.

10. Bhavesh, R.N.; Kishor, S.P.; Manish, M.J.; Mayur, R.P. Synthesis and antimicrobial activity of some new isatin derivatives. Der Pharma Chemica 2011, 3, 367-372.

11. Madhu; Priyanka, B.; Maharaj; Krishnaveni, J.; Brahmeswari, G.; Sarangapani, M.; Sammaiah, G. Synthesis and antimicrobial activity of some new isatin derivatives. J. Adv. Pharm. Sci. 2011, 1, $10-15$.

12. Naumov, P.; Anastasova, F. Experimental and theoretical vibrational stydy of isatin, its 5-( $\mathrm{NO}_{2}$, $\left.\mathrm{F}, \mathrm{Cl}, \mathrm{Br}, \mathrm{I}, \mathrm{CH}_{3}\right)$ analogues and the isatinato anion. Spectrochim. Acta A Mol. Biomol. Spectrosc. 2001, 57, 469-481.

13. Anastasova, F.B. Synthesis of Heterocyclic Azomethynes with Potential Biological Activity. Ph.D. Thesis, Faculty of Science, Sts. Cyril and Methodius University, Skopje, Macedonia, 1997.

14. Pandeya, S.N; Smitha, S.; Jyoti, M.; Sridhar, S.K. Biological activities of isatin and its derivatives. Acta Pharm. 2005, 55, 27-46.

15. Natarajan, A.; Fan, Y.H.; Chen, H.; Guo, Y.; Iyasere, J.; Harbinski, F.; Christ, W.J.; Aktas, H.; Halperin, J.A. 3,3-Diaryl-1,3-dihydroindol-2-ones as antiproliferatives mediated by translation initiation inhibition. J. Med. Chem. 2004, 47, 1882-1885.

16. Matheus, M.E.; Violante, F.D.A.; Garden, S.J.; Pinto, A.C.; Fernandes, P.D. Isatins inhibit cyclooxigenase-2 and inducible nitric oxide synthase in a mouse macrophage cell line. Eur. J. Pharmacol. 2007, 556, 200-206.

17. Zhou, L.; Liu, Y.; Zhang, W.; Wei, P.; Huang, C.; Pei, J.; Yuan, Y.; Lai, L. Isatin compounds as noncovalent SARS coronavirus 3C-like protease inhibitors. J. Med. Chem. 2006, 49, 3440-3443.

18. Kang, I.J.; Wang, L.W.; Hsu, T.A.; Yueh, A.; Lee, C.C.; Lee, Y.C.; Lee, C.Y.; Chao, Y.S.; Shih, S.R.; Chern, J.H. Isatin- $\beta$-thiosemicarbazones as potent herpes simplex virus inhibitors. Bioorg. Med. Chem. Lett. 2011, 21, 1948-1952.

19. Hall, M.D.; Salam, N.K.; Hellawell, J.L.; Fales, H.M.; Kensler, C.B.; Ludwig, J.A.; Szakács, G.; Hibbs, D.E.; Gottesman, M.M. Synthesis, activity, and pharmacophore development for isatinbeta-thiosemicarbazones with selective activity toward multidrug-resistant cells. J. Med. Chem. 2009, 52, 3191-3204.

20. Kiran, G.; Maneshwar, T.; Rajeshwar, Y.; Sarangapani, M. Microwave-assisted synthesis, characterization, antimicrobial and antioxidant activity of some new isatin derivatives. J. Chem. 2013, 2013, doi:10.1155/2013/192039. 
21. Da Silva, J.F.M.; Garden, S.J.; Pinto, A.C. The Chemistry of isatins: A review from 1975 to 1999. J. Braz. Chem. Soc. 2001, 12, 273-324.

22. Boechat, N.; Kover, W.B.; Bastos, M.M.; Romeiro, N.C.; Silva, A.S.C.; Santos, F.C.; Velverde, A.L.; Azevedo, M.L.G.; Wollinger, W.; Souza, T.M.L.; et al. Design, synthesis, and biological evaluation of new 3-hydroxy-2-oxo-3-trifluoromethylindole as potential HIV-1 reverse transcriptase inhibitors. Med. Chem. Res. 2007, 15, 492-510.

23. Zhou, J.; Wu, D.; Guo, D. Optimization of the production of thiocarbohydrazide using the Taguchi method. J. Chem. Technol. Biot. 2010, 85, 1402-1406.

24. Konstantinović, S.S.; Kapor, A.; Radovanović, B.C.; Deak, A. Synthesis, X-ray and antimicrobial activity of isatin-3-phenylhydrzone. Chem. Ind. Chem. Eng. Q. 2008, 14, $27-34$.

25. Wang, H.-Y.; Xu, C.; Zhu, W.; Liu, G.-S.; Guo, Y.-L. Gas phase decarbonylation and cyclization reactions of protonated $N$-methyl- $N$-phenylmethacrylamide and its derivatives via an amide Claisen rearrangement. J. Am. Soc. Mass Spectrom. 2012, 23, 2149-2157.

(C) 2013 by the authors; licensee MDPI, Basel, Switzerland. This article is an open access article distributed under the terms and conditions of the Creative Commons Attribution license (http://creativecommons.org/licenses/by/3.0/). 